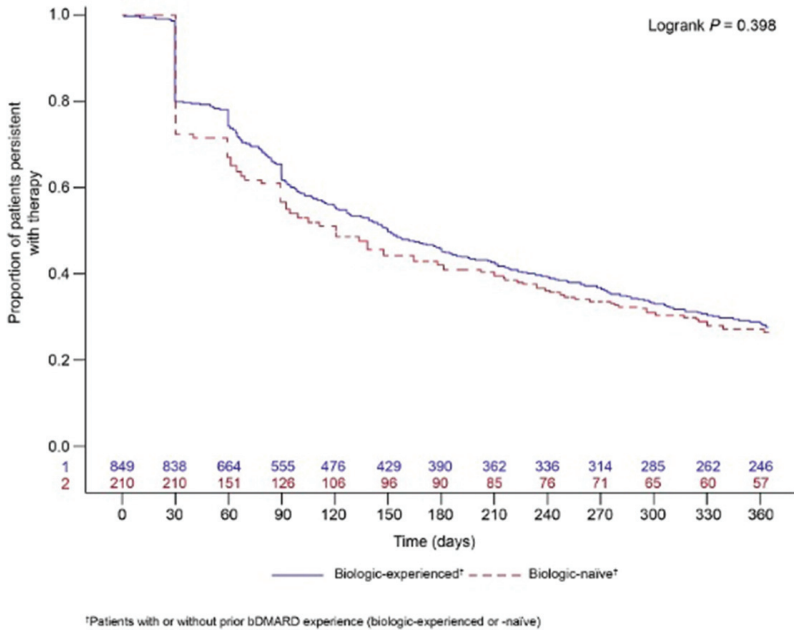

Figure 1 Kaplan-Meier curve of persistence with JAKI therapy

Conclusions: Most patients (80.2\%) newly initiating JAKi therapy had prior bDMARD experience. Over $70 \%$ were non-persistent with JAKi treatment for 1 year, with $39 \%$ non-persistent beyond 90 days. For non-persistent patients, the pattern of JAKi use was characterized most as interrupting with restart (42\%), followed by switching $(30 \%)$, and then discontinuation (28\%). Reasons for the high non-persistence rate are unknown but may include suboptimal efficacy or intolerance. Further research is needed to elucidate these points.

Acknowledgements: Research sponsored by Sanofi and Regeneron Pharmaceuticals, Inc.

Disclosure of Interest: B. Chastek Grant/research support from: Sanofi and Regeneron Pharmaceuticals, Inc., E. Koep Grant/research support from: Sanofi and Regeneron Pharmaceuticals, Inc., U. Mallya Shareholder of: Sanofi, Employee of: Sanofi, A. Cockerham Employee of: Sanofi, J. Choi Shareholder of: Sanofi, Employee of: Sanofi, S. Boklage Shareholder of: Regeneron Pharmaceuticals, Inc., Employee of: Regeneron Pharmaceuticals, Inc., D. Furst Grant/ research support from: Amgen, Bristol-Myers Squibb, Novartis, Sanofi-Regeneron, Pfizer, Roche/Genentech, and Corbus, Consultant for: AbbVie, Amgen, Bristol-Myers Squibb, Corbus, Cytori, Novartis, Pfizer, and Roche/Genentech, Speakers bureau: Bristol-Myers Squibb and Abbvie

DOI: 10.1136/annrheumdis-2018-eular.3456

\section{SAT0178 PREDICTORS OF DRUG SURVIVAL OF ABATACEPT IN RHEUMATOID ARTHRITIS - RESULTS FROM A LARGE NATIONAL QUALITY REGISTER COHORT STUDY}

G. Cagnotto ${ }^{1,2}$, M. Willim ${ }^{2,3}$, J.-Å. Nilsson ${ }^{1,2}$, S. Saevarsdottir ${ }^{4}$, C. Turesson ${ }^{1,2}$.

${ }^{1}$ Rheumatology, Department of Clinical Sciences, Malmö, Lund University, ${ }^{2}$ Department of Rheumatology, SKÅNE UNIVERSITY HOSPITAL, Malmö, ${ }^{3}$ Rheumatology, Department of Clinical Sciences, Lund, Lund University, Lund, ${ }^{4}$ Rheumatology Unit, Department of Medicine, Solna, Karolinska Institutet, Stockholm, Sweden

Background: Abatacept is a biologic disease modifying anti-rheumatic drug (bDMARD) used to treat rheumatoid arthritis (RA). There is growing experience with abatacept in many countries. National registers are useful resources for investigation of long term real world outcomes.

Objectives: To compare the effectiveness of abatacept in the treatment of RA between bionaïve patients and patients with previous bDMARD treatment, and to investigate predictors of remaining on treatment with abatacept.

Methods: This was an observational cohort study, based on a national quality register database. Patients with a diagnosis of RA who initiated treatment with abatacept between April 1, 2006 and November 20, 2017, were included. Patients were censored at abatacept discontinuation, death, migration, or the end of the study period. Analyses were stratified by previous exposure to bDMARDs. Survival on drug was estimated using the Kaplan-Meier method. Predictors of discontinuation of abatacept were investigated in Cox Proportional Hazards analyses, with significance-based backwards stepwise selection of variables for the final multivariate model.

Results: A total of 2716 patients with RA ( $80 \%$ females, mean age 59 years, mean duration of RA 14 years) started abatacept during the study period. Of these, $17 \%$ had no previous bDMARD treatment (bionaïve patients), $27 \%$ had received 1 bDMARD previously, and $56 \%$ had been treated with $\geq 2$ bDMARDs.
Fifty percent each of the patients received intravenous and subcutaneous therapy. At the time of abatacept initiation, $57 \%$ were on methotrexate (MTX), and 48 $\%$ were treated with glucocorticosteroids. There were significant differences in drug survival across categories of previous bDMARD exposure $(p=0.002)$. The median survival time on treatment was 2.23 years for bionaïve patients $(95 \%$ confidence interval (Cl) 1.69-2.79)), 1.68 years for those with 1 previous bDMARD $(95 \% \mathrm{Cl} 1.34-2.01)$ and 1.56 years for those with $\geq 2$ previous bDMARDs $(95 \%$ $\mathrm{Cl} 1.35-1.76)$. At 6 months, $88 \%$ of bionaïve patients remained on abatacept, compared to $74 \%$ at 12 months. The corresponding figures for those with 1 or $\geq 2$ previous bDMARDs were $78 \%$ and $61 \%$, and $76 \%$ and $59 \%$, respectively. In bivariate analyses, bionaïve patients were less likely to discontinue treatment compared to those treated with $\geq 2$ previous bDMARDs previously (Table). Bionaïve patients were more often male ( $28 \%$ vs $18 \%$ ) and had lower pain scores (mean Visual analogue scale score 58 vs 62 ) compared to those previously exposed to $\geq 2$ bDMARDs. Measures of disease severity were associated with reduced drug survival (Table), but age, RA duration and method of administration had no significant impact on discontinuation. In the final multivariate model, pain increased the risk of abatacept discontinuation, whereas male patients and those on concurrent MTX had a reduced risk of stopping abatacept (Table).

Significant predictors for abatacept discontinuation. Cox regression analysis

\begin{tabular}{|l|l|c|c|}
\hline & & Unadjusted analysis & $\begin{array}{c}\text { Multivariate analysis } \\
- \text { final model } \\
\text { HR }(95 \% \mathrm{CI})\end{array}$ \\
\hline Sex & Male & $0.85(0.75-0.96)$ & $0.86(0.74-0.98)$ \\
\hline \multirow{2}{*}{$\begin{array}{l}\text { No of previous } \\
\text { bDMARDs }\end{array}$} & $\geq 2$ bDMARDs & reference $(1.0)$ & $*$ \\
\cline { 2 - 4 } & Bionaive & $0.78(0.68-0.90)$ & $*$ \\
\cline { 2 - 4 } & 1 bDMARD & $0.94(0.84-1.05)$ & $*$ \\
\hline \multirow{3}{*}{$\begin{array}{l}\text { Baseline clinical } \\
\text { characteristics }\end{array}$} & DAS28-CRP (per SD) & $1.11(1.04-1.17)$ & $*$ \\
\cline { 2 - 4 } & VAS pain (per SD) & $1.14(1.08-1.21)$ & $1.14(1.07-1.20)$ \\
\cline { 2 - 4 } & Current Methotrexate & $0.86(0.78-0.96)$ & $0.85(0.76-0.95)$ \\
\cline { 2 - 4 } & HAQ-DI (per SD) & $1.10(1.04-1.17)$ & $*$ \\
\hline
\end{tabular}

*Not included in the final model

Figure 1. Significant predictors for abatacept discontinuation. Cox regression analysis ${ }^{\star}$ Not included in the final mode

Conclusions: Survival on abatacept was significantly longer in bionaïve RA patients compared to those previously exposed to bDMARDs. In the bionaĩve sub set, $50 \%$ of the patients remained on treatment after 2.2 years. Concomitant MTX therapy, male sex and low pain scores were associated with longer drug survival for abatacept.

Disclosure of Interest: G. Cagnotto Paid instructor for: Novartis, M. Willim: None declared, J.-Å. Nilsson: None declared, S. Saevarsdottir: None declared, C. Turesson Grant/research support from: Abbvie, Bristol Myers-Squibb, Roche. The present study was supported by an unrestricted grant from Bristol MyersSquibb, Consultant for: MSD, Bristol Myers-Squibb, Roche, Paid instructor for: Abbvie, Bristol-Myers Squibb, Janssen, MSD, Pfizer, Roche and UCB

DOI: 10.1136/annrheumdis-2018-eular.1697

\section{SAT0179 THE BLOOD B-CELL SUBSETS AND EFFECT OF TOCILIZUMAB THERAPY ON THEM IN PATIENTS WITH RHEUMATOID ARTHRITIS}

E. Gerasimova ${ }^{1}$, T. Popkova ${ }^{2}$, A. Aleksankin ${ }^{2}$, S. Davidyan ${ }^{3}$, A. Martinova ${ }^{2}$, E. Aleksandrova' ${ }^{2}{ }^{1} 34$ A, Kashirskoe Shosse, Gerasimova Elena, ${ }^{2} 34$ A, Kashirskoe Shosse, ${ }^{3}$ V.A.Nasonova Research Institute of Rheumatology, Moscow, Russian Federation

Background: The use of the IL-6 receptor antagonist, tocilizumab (TCZ), in rheumatoid arthritis (RA) produce pleiotropic effects that also involve circulating $B$-cells. Preliminary reports have suggested that B cell function and humoral immune responses might be modulated by TCZ treatments in RA pts.

Objectives: To assess the effect of 12 month (mo) TCZ therapy on B-cell phenotype and gene expression in RA and to analyze the association between B-cell subsets and RA activity

Methods: 24 active RA pts (20 F/4 M); median age 55[49; 64] years; disease duration 72[24; 108]m; DAS28 score 5,8[5,3;6,3]; RF+100\%, ACCP+ $87 \%$ were treated in an open-label study with tocilizumab ( $8 \mathrm{mg} / \mathrm{kg}$ every 4 weeks). Immunophenotyping was performed at baseline and 12 mo. Pts were assessed for B-cell subpopulations and laboratory data: ESR, RF, ACCP, CRP. CD19+B cells, memory B cells (CD19+CD27+), non-switched memory B cells (CD19+CD27+ IgD+), switched memory B cells (CD19+ CD27+lgD-), naive (CD19+CD27-lgD+), dou ble-negative (CD19+CD27-lgD-), transitional (CD19+CD38++CD10+lgD+CD27-) B cells, and plasmablasts (CD19+CD38+++CD27+lgD-CD20-) were analyzed using multicolor flow cytometry.

Results: At baseline, the absolute counts of memory B cells (CD19+CD27+) and switched memory B cells (CD19+CD27+lgD-) were lower in RA pts compared to 